\title{
Legal Protection to Commercial Sex Workers (PSK) Viewed From Reproductive Health Aspects at Pasar Kembang (Sarkem) Yogyakarta
}

\author{
Perlindungan Hukum Terhadap Pekerja Seks Komersial (PSK) \\ Ditinjau Dari Aspek Kesehatan Reproduksi \\ di Pasar Kembang (Sarkem) Yogyakarta \\ Tyas Kartika Siwi, Agnes Widanti, Hartanto \\ email: tyaskartika63@yahoo.com \\ Health Law Master Program, Soegijapranata Catholic University of Semarang
}

\begin{abstract}
All women had equal rights to reproductive health, no exception for commercial sex workers (PSK), because PSK was a very risky job for various diseases, among others, gonorrhea, herpes, fungal infections, syphilis, vaginitis, ulcers, sex lice, and HIV/AIDS. However, in reality, not all PSKs got their rights to reproductive health. The Government had issued a regulation related to reproductive rights, namely Government Regulation Nr. 61 of 2014 on Reproductive Health.
\end{abstract}

This research used the socio-legal approach with the analytical- descriptive specification. The primary data were obtained from interviews with the Head of Public Health Center (Puskesmas) of Gedongtengen, doctors, midwives, coordinator of commercial sex workers association, AIDS Prevention Commission, the Head of Infectious Disease Control Section of the Health Office of Yogyakarta City, hotel owners and commercial sex workers (PSK). Secondary data were obtained from books and legal materials having relations with the research. The data gathered were then qualitatively analyzed.

The results of the research at Puskesmas of Gedongtengen showed that PSK had obtained legal protection by the contents of articles of the prevailing legislation and the Minister of Health's regulation. Puskesmas of Gedongtengen had reproductive health services programs such as clinical sexual services of sexually transmitted infections (STI) and voluntary counseling and testing (VCT). If by an examination a PSK was found HIV/AIDS positive, she would be referred to a hospital having facilities by her needs. On the one hand, the supporting factors of the implementation of legal protection to commercial sex workers regarding reproductive health included affordable costs of the Puskesmas, availability of competent health personnel, adequate facilities, and infrastructure, cross-sectoral cooperation, PSK involvement in the services provided. On the other hand, the inhibiting factors were the absence of specific legislative regulations on PSK, low-level education that led to lack of health examination awareness, a lot of the customers that refused to use condoms and the insufficient availability of skilled health personnel.

Keywords: reproductive health, commercial sex workers, legal protection. 


\section{PENDAHULUAN}

Kesehatan sebagai salah satu unsur kesejahteraan umum harus diwujudkan melalui berbagai upaya kesehatan dalam rangka pembangunan kesehatan secara menyeluruh dan terpadu yang didukung oleh suatu sistem kesehatan nasional. ${ }^{1}$ Pasal 28 ayat (1) UndangUndang Dasar Tahun 1945 dengan jelas menekankan bahwa setiap orang berhak hidup sejahtera lahir dan batin, bertempat tinggal dan mendapatkan lingkungan hidup yang baik dan sehat serta berhak memperoleh pelayanan kesehatan. Artinya kesehatan sebagai kebutuhan dasar manusia merupakan hak bagi setiap warga negara. Pasal 47 UndangUndang Nomor 36 Tahun 2009 tentang Kesehatan membahas tentang upaya pelayanan kesehatan yaitu "upaya kesehatan diselenggarakan dalam bentuk kegiatan dengan pendekatan promotif (penigkatan kesehatan), preventif (pencegahan penyakit), kuratif (pencegahan penyakit), serta rehabilitatif (pemulihan kesehatan), yang dilaksanakan secara terpadu, menyeluruh, dan berkesinambungan".

Hak atas kesehatan reproduksi adalah milik semua perempuan khususnya bagi Pekerja Seks Komersial (PSK) yang merupakan kaum rawan akan gangguan kesehatan reproduksi. Komisi Penanggulangan AIDS (KPA) memiliki program yaitu memonitoring dan mendistribusikan alat kontrasepsi kondom secara gratis ke 25 outlet sehingga sampai ke lokasi-lokasi rawan.

PSK adalah pekerjaan yang memiliki resiko untuk menimbulakn berbagai penyakit yang membahayakan bagi kepribadian seseorang, serta memperburuk kehidupan keluarga dan pernikahan. Dampak penyakit yang ditimbulkan antara lain: gonore, herpes, infeksi jamur, sifilis, vaginitis, bisul, kutu kelamin, dan HIV/AIDS. ${ }^{2}$ Demi mewujudkan hak bagi PSK didirikan panti rehabilitasi untuk membantu para PSK agar berhenti menjadi PSK. Beberapa tawaran dana dari pemerintah dianggap belum cukup untuk memberikan pelatihan serta modal bagi semua PSK. Pekerja seks komersial adalah salah satu bagian dari dunia pelacuran yang didalamnya termasuk gigolo, waria, dan mucikari. Dalam pelayanan kesehatan semua orang memiliki perlakuan hak yang sama tanpa diskriminasi, termasuk pekerja seks komersial.

Tenaga kesehatan memiliki peran penting dalam memberikan pelayanan kesehatan, terutama pelayanan kesehatan reproduksi khususnya untuk PSK. Kepala Puskesmas Gedongtengen, mendapatkan tugas mengikuti pertemuan dengan pihak pengelola lembaga swadaya masyarakat, keamanan dan para tokoh di wilayah Pasar Kembang, untuk menjalankan program Pusat Layanan Kesehatan Klinik IMS dan VCT karena sebelumnya terjadi 13 kasus HIV di Sarkem pada Tahun 2014 dan 19 kasus HIV pada Tahun 2016.

Semua orang berhak mendapatkan pelayanan kesehatan reproduksi tanpa terkecuali seorang PSK, karena kegiatan yang mereka lakukan rentan akan penyakit menular seksual. Penularan bisa terjadi dari PSK ke pelanggan, pelanggan ke istri dan kemudian istri ke janin (kandungan). Hal ini sesuai dengan Pasal 30 ayat (1) Peraturan Pemerintah Republik Indonesia Nomor 61 Tahun 2014 tentang Kesehatan Reproduksi bahwa "setiap perempuan berhak atas pelayanan kesehatan sisten reproduksi". Kesehatan merupakan hak setiap manusia dan dilindungan oleh Undang-Undang, tidak terkecuali seorang PSK. sehingga penting bagi tenaga kesehatan untuk memberikan pelayanan kesehatan sesuai dengan

\footnotetext{
${ }^{1}$ Cecep Triwibowo, 2014, Etika dan Hukum Kesehatan, Yogyakarta: Nuha Medika, Hal, 13.

${ }^{2}$ Eny Retna Ambarwati,Y, Sriati Rismintari, 2009, Asuhan Kebidanan Komunitas, Yogyakarta: Nuha Medika,Hal, 3141.
} 
kebutuhan agar dapat mengurangi penyebaran penyakit menular seksual yang diakibatkan oleh PSK.

\section{PERUMUSAN MASALAH}

1. Bagaimana peraturan yang mengatur tentang perlindungan hukum terhadap pekerja seks komersial ditinjau dari aspek kesehatan reproduksi di Pasar Kembang (Sarkem) Yogyakarta?

2. Bagaimanakah pelaksanaan perlindungan hukum terhadap pekerja seks komersial ditinjau dari aspek kesehatan reproduksi di Pasar Kembang (Sarkem) Yogyakarta?

3. Apakah faktor pendukung dan penghambat pelaksanaan perlindungan hukum terhadap kesehatan reproduksi pekerja seks komersial di Pasar Kembang (Sarkem) Yogyakarta?

\section{METODE PENELITIAN}

Penelitian ini menggunakan metode yuridis sosiologis dengan pendekatan deskriptif analitis. Jenis data terdiri dari data primer yaitu hasil wawancara responden dan narasumber, serta data sekunder yaitu teori yang diperoleh dari buku serta peraturan perundang-undangan sesuai dengan judul tesis. Penelitian ini dilakukan di Puskesmas Gedongtengen dengan mewawancarai narasumber seperti (dokter, bidan, kepala puskesmas, kelompok perhimpunan perempuan pekerja seks komersial, pemilik losmen, kepala seksi pengendalian penyakit menular dinas kesehatan Kota Yogyakarta, pengelola program komisi penanggulangan AIDS).. Metode analisis data menggunakan kualitatif.

\section{PEMBAHASAN}

1. Peraturan Yang Mengatur Tentang Perlindungan Hukum Terhadap Pekerja Seks Komersial Di Tinjau Dari Aspek Kesehatan Reproduksi Di Pasar Kembang (Sarkem) Yogyakarta

Indonesia belum mempunyai peraturan yang mengatur tentang larangan adanya pekerja seks komersial. Karena tidak adanya peraturan perundang-undangan, menyebabkan tidak ada kepastian hukum dan kekosongan hukum terkait PSK. Meskipun demikian, terdapat beberapa peraturan lain yang didalam pasal tersebut menyatakan bahwa setiap orang dan setiap perempuan berhak atas pelayanan kesehatan sistem reproduksi. Berikut beberapa produk hukum yang berkaitan dengan bentuk perlindungan yang diberikan kepada PSK, terdapat didalam: Undang-Undang Dasar 1945, Pasal 28 H ayat (1) dan Pasal 28 D. Dalam Kedua pasal tersebut telah dijelaskan bahwa kesehatan adalah hak setiap orang dan wajib dilindungi oleh hukum.

Undang-Undang Nomor 36 Tahun 1999 tentang Hak Asasi Manusia, Pasal 3 ayat (2) dan Ayat (3), Pasal 49 ayat (2) dan Ayat (3). Berdasarkan hasil analisis Undang-Undang Nomor 36 Tahun 1999 tentang Hak Asasi Manusia, dapat ditarik kesimpulan bahwa, setiap orang, setiap perempuan, memiliki jaminan kesehatan, perlindungan hukum, dan hak asasi manusia tanpa diskriminasi, telah diatur dalam undang-undang yang berlaku. Dalam hal ini Puskesmas Gedongtengen telah memberikan hak kepada semua orang, perempuan atas jaminan kesehatan, perlindungan hukum dan hak asasi manusia, dalam bentuk pelayanan kesehatan reproduksi. Berkaitan dengan hak kesehatan reproduksi, bahwa hak perempuan adalah Hak untuk mendapatkan pelayanan dan 
perlindungan kesehatan reproduksi dan hak asasi tanpa bentuk tindak diskriminasi. Hal ini sesuai dengan temuan dilapangan bahwa PSK yang berada dikawasan Sarkem telah mendapatkan hak pelayanan kesehatan reproduksi dengan sangat baik, aman dan bermutu.

Undang-Undang Nomor 36 Tahun 2009 tentang Kesehatan, Pasal 4, Pasal 5 ayat (1) dan ayat (2), Pasal 8, Pasal 16, Pasal 17, Pasal 47, Pasal 48 ayat (1) dan Ayat (2), Pasal 54 ayat (1), Pasal 63 ayat (2), Pasal 71 ayat (3), Pasal 74 ayat (1), Pasal 152 ayat (3). Berdasarkan hasil analisis Undang-Undang Nomor 36 Tahun 2009 tentang Kesehatan menegaskan bahwa, setiap orang mempunyai hak yang sama dalam memperoleh akses atas sumber daya di bidang kesehatan. Pembangunan kesehatan pada hakekatnya diarahkan guna tercapainya kesadaran, kemauan dan kemampuan hidup sehat bagi setiap orang. Berdasarkan penelitian yang telah dilakukaan, hal ini sesuai dengan yang ditemukan di lapangan bahwa dalam pembangunan kesehatan Dinas Kesehatan Kota Yogyakarta dengan tim STBM dibantu dengan LSM dan Puskesmas Gedongtengen telah berupaya memberikan pelayanan kesehatan reproduksi untuk menurunkan angka penyakit menular seksual dan HIV/AIDS secara aman, bertanggung jawab dan berkesinambungan.

Undang-Undang Nomor 36 Tahun 2014 tentang Tenaga Kesehatan, Pasal 62 ayat (1) huruf c. Berdasarkan hasil analisis Undang-Undang Nomor 36 Tahun 2014 tentang Tenaga Kesehatan dan hasil penelitian didapatkan Puskesmas Gedongtengen telah memberikan berbagai pelatihan kepada dokter, bidan, perawat dan apoteker. Tujuan dari pelatihan tersebutagar tenaga kesehatan memiliki wewenang dalam memberikan pelayanan sesuai dengan standar oprasional prosedur yang berlaku, serta diharapkan mampu mengabdikan diri kepada masyarakat khususnya untuk PSK di Sarkem, agar dapat memberikan pelayanan kesehatan yang layak dan sesuai dengan kebutuhan PSK.

Peraturan Pemerintah Nomor 61 Tahun 2014 tentang Kesehatan Reproduksi, Pasal 3, Pasal 5, Pasal 30 ayat (1) dan Ayat (2). Berdasarkan hasil analisis Peraturan Pemerintah Nomor 61 Tahun 2014 tentang Kesehatan Reproduksi bahwa, dalam memberikan pelayanan kesehatan reproduksi bagi PSK tenaga kesehatan Puskesmas Gedongtengen telah memberikan pelayanan yang aman, bermutu dan dapat dipertanggungjawabkan, seperti Pusat Layanan Kesehatan Klinik IMS dan VCT.

Untuk melindungi Perempuan Pekerja Seks yang mengalami kekerasan dalam bentuk ancaman dan fisik, kemudian tindak diskriminasi maka bentuk perlindungan hukum terdapat pada kesepakatan konfrensi internasional ICPD tahun 1994 di Kairo, pemerintah Indonesia telah menyetujuai 12 hak yang mana salah satu hak untuk bebas dari penganiayaan dan perlakuan buruk, termasuk perlindungan dari perkosaan, kekerasan, penyiksaan, dan pelecehan seksual karena setiap perempuan berhak untuk dilindungi dari ancaman bentuk-bentuk kekerasan yang dapat menimbulkan penderitaan secara fisik, seksual, dan psikis yang mengganggu kesehatan fisik, mental dan reproduksinya.

2. Pelaksanaan perlindungan hukum terhadap pekerja seks komersial di tinjau dari aspek kesehatan reproduksi di Pasar Kembang (Sarkem) Yogyakarta

Pelaksanaan perlindungan hukum di Sarkem untuk PSK yaitu pelayanan kesehatan yang diberikan oleh tenaga kesehatan Puskesmas Gedongtengen antara lain: konseling kesehatan reproduksi dan seksusl, konseling infeksi menular seksual (IMS), konseling HIV dan AIDS, periksa IVA/Pap Smear, periksa umum, Tes IMS dan HIV. Pemeriksaan VCT, IMS, HR, LJSS, dan PTRM (program terapi rumatan metadon) serta klinik berhenti merokok. Pemeriksaan tersebut biasanya dilakukan setiap satu bulan sekali, per tiga 
bulan sekali atau enam bulan sekali dan satu tahun sekali. Dan bentuk perlindungan lainnya yaitu pembagian kondom secara gratis yang dilakukan oleh Komisi Penanggulangan AIDS. Dengan adanya program tersebut bertujuan untuk mengupayakan pengurangan terjadinya penularan IMS dikalangan PSK.

Mekanisme pelayanan kesehatan reproduksi yang dilakukan dokter dan bidan dalam untuk PSK di Sarkem yaitu, dilakukan sesuai dengan bulan yang sudah terjadwal, untuk pelayanan bisa dilakukan di Puskesmas atau di Sarkem. Pertama P3SY akan mendata PSK yang ada di Sarkem kemudia tenaga kesehatan kesehatan Puskesmas Gedongtengen akan mulai memberikan pelayanan kepada PSK satu persatu, kemudian pemeriksaan akan dilakukan oleh dokter dan bidan dibantu perawat dan P3SY juga.

Puskesmas Gedongtengan telah memberikan pelayanan yang sudah sesuai dengan kebutuhan PSK. Ditunjang dari program Pusat Layanan Kesehatan Klinik IMS serta layanan komprehensif berkesinambungan (LKB), selain itu beberapa tenaga kesehatan seperti dokter umum, bidan, perawat, dokter psikologi telah mengikutibeberapa pelatihan dan telah mendapatkan sertifikat guna menunjang pelayanan kesehatan reproduksi yang akan diberikan bagi PSK. Seluruh tenaga kesehatan seperti dokter, bidan, perawat, psikolog dan apoteker yang berada di Puskesmas Gedongtengen telah melaksanakan perannya sesuai dengan kompetensi dan wewenang.

3. Faktor Pendukung dan Penghambat penghambat pelaksanaan perlindungan hukum terhadap kesehatan reproduksi pekerja seks komersial di Pasar Kembang (Sarkem) Yogyakarta

a. Faktor pendukung

1) Ketersediaan tenaga kesehatan yang sudah kompeten.

Faktor pendukung perlindungan hukum terhadap kesehatan reproduksi PSK yaitu tenaga kesehatan yang sudah berkompeten dalam memberikan hak PSK dalam bentuk pelayanan kesehatan dan informasi mengenai kesehatan reproduksi.

2) Program layanan kesehatan klinik IMS dan VCT

Upaya pemerintah dalam menyediakan akses terhadap informasi, edukasi dan fasilitas kesehatan telah dilaksanakan oleh Puskesmas Gedongtengen yaitu dilihat dari tujuan program layanan kesehatan klinik IMS dan VCT bertujuan untuk menekan angka penyebaran penularan penyakit menular seksual dan pengobatan pada PSK yang positif IMS atau HIV/AIDS.

3) Pelatihan tenaga kesehatan.

Upaya lain yang dilakukan oleh Puskesmas Gedongtengen yaitu melakukan pelatihan kepada beberapa tenaga kesehatan bertujuan untuk menunjang pelayanan kesehatan yang aman dan bermutu khususnya pelayanan kesehatan reproduksi untuk PSK. Berikut tenaga kesehatan yang sudah terlatih untuk melakukan pemeriksaan kesehatan reproduksi kepada PSK, antara lain 2 dokter, 2 bidan dan 3 perawat.

4) Sarana dan prasarana yang cukup memadai.

Puskesmas adalah suatu kesatuan organisasi fungsional yang langsung memberikan pelayanan secara menyeluruh kepada masyarakat dalam suatu 
wilayah kerja tertentu dalam bentuk-bentuk usaha kesehatan. ${ }^{3}$ Sebagai salah satu pusat pelayanan kesehatan pertama Puskesmas Gedongtengen, telah didukung dengan sarana dan prasarana yang cukup memadai. Seperti mobile clinik serta tenaga kesehatan yang sudah berkompeten dan mampu memberikan pelayanan kesehatan sesuai dengan standar SOP.

5) Kerja sama lintas sektor yang telah dilakukan.

Dalam usaha pencegahan penularan penyakit menular seksual, puskesmas gedongtengen telah bekerja sama dengan berbagai pihak untuk memberikan standar pelayanan yang lebih baik. Kerja sama yang dilakukan dengan lintas sektor antara lain: Dinas Kesehatan Kota Yogyakarta, Komisi Penanggulangan AIDS, P3SY, serta kerja sama dengan Rumah Sakit untuk penanganan PSK dengan HIV/AIDS. Tidak hanya itu, program pencegahan HIV/AIDS menpunyai prinsif dengan melibatkan PSK yang positif HIV/AIDS yang mau berpartisipasi dan yang menjadi pembicara satu orang PSK bertujuan untuk mempromosikan pentingnya menjaga kesehatan reproduksi dan memberi motivasi kepada PSK.

b. Faktor penghambat

1. Belum terdapat peraturan perundang-undangan khusus tentang PSK.

Belum terdapat peraturan khusus tentang PSK, Menjadi faktor penghambat pelaksanaan perlindungan hukum terkait dengan kesehatan reproduksi PSK.

2. Wajib menggunakan kondom

Sebagai pengguna jasa PSK seharusnya pelanggan mematuhi peraturan yang ada yaitu wajib kondom. Menurut keterangan PSK terdapat pelanggan yang enggan menggunakan kondom setelah berada di dalam kamar dengan alasan mengurangi kenikmatan. Terkadang PSK menuruti permintaan pelanggan demi mendapatkan lebih tambahan upah.

3. Rendahnya tingkat pendidikan dan tingkat ekonomi PSK.

Motivasi menjadi PSK tentu banyak faktornya, misalnya karena himpitan ekonomi, tidak memiliki keterampilan dan keahlian, dijebak oleh tipuan agen tenaga kerja, dan ada pula yang melakukan secara tidak terpaksa/keinginan sendiri untuk mencari pasangan yang sesuai dengan kriterianya. Kepadatan penduduk yang terjadi dibeberapa daerah berdampak pada pembangunan daerah yang belum merata, hal itu dapat dilihat dari status pendidikan PSK yang masih rendah dan masih tingginya angka penduduk miskin. Mengakibatkan penduduk desa datang ke kota, dengan harapan akan merubah status sosial seseorang jika telah bekerja di kota. Karena untuk mendapatkan pekerjaan yang layak dibutuhkan pengetahuan, keterampilan dan tentutunya lulusan pendidikan sekurang-kurangnya sekolah menengah atas.

4. Rendahnya kesadaran PSK untuk melakukan pemeriksaan.

Berdasarkan hasil wawancara dengan tenaga kesehatan puskesmas gedongtengen, PSK tidak memiliki inisiatif untuk datang langsung ke Puskesmas, tetapi jika tenaga kesehatan datang ke lokasi Sarkem PSK dengan senang hati mau diperiksa kesehatannya.

${ }^{3}$ Arisita Eka Prasetyawati, 2011, Ilmu Kesehatan Masyarakat untuk Kebidanan Holistik, Yogyakarta, Nuha Medika, Hal, 121. 
5. Ketersediaan tenaga kesehatan

Tenaga kesehatan terlatih dirasa belum cukup mampu untuk melakukan penanganan kesehatan reproduksi kesemua PSK.

\section{PENUTUP}

\section{KESIMPULAN}

1. Peraturan yang mengatur tentang perlindungan hukum terhadap pekerja seks komersial ditinjau dari aspek kesehatan reproduksi di pasar kembang sarkem: Belum terdapat peraturan mengenai perlindungan hukum pekerja seks komersial tetapi dalam permenkes dan undang-undang terdapat ketentuan umum mengenai perlindungan kesehatan reproduksi.

2. Pelaksanaan perlindungan hukum terhadap pekerja seks komersial ditinjau dari aspek kesehatan reproduksi: tenaga kesehatan sudah melaksanakan perlindungan hukum melalui program pelayanan kesehatan reproduksi khususnya bagi pekerja seks komersial yaitu pencegahan IMS dan VCT.

3. Faktor pendukung dan faktor penghambat pelaksanaan perlindungan hukum terhadap pekerja seks komersial ditinjau dari aspek kesehatan reproduksi di pasar kembang sarkem: faktor pendukung ntara lain ketersediaan tenaga kesehatan yang berkompeten, sarana dan prasarana yang cukup memadai, kerja sama lintas sektor, serta biaya puskesmas yang terjangkau. Sedangkan faktor penghambat yaitu belum terdapat peraturan perundang-undangan mengenai PSK, rendahnya tingkat pendidikan menyebabkan rendahnya kesadaran PSK untuk melakukan pemeriksaan kesehatan dan banyaknya pelanggan yang menolak menggunakan kondom serta ketersediaan tenaga kesehatan terampil belum mencukupi.

\section{SARAN}

1. Puskesmas Gedongtengen

Harus meningkatkan fasilitas kesehatan, peningkatan kapasitas, monitoring, pendampingan dan menyediakan SDM yang terlatih khusus untuk memberikan pelayanan kesehatan reproduksi sehingga dapatmenekan atau mengurangi penyebaran infeksi menular seksual (IMS) dan HIV/AIDS pada PSK.

2. Tenaga kesehatan

Sebagai Dokter, bidan, perawat, harus senantiasa meningkatkan pengetahuan dan keterampilan dengan mengikuti pelatihan terkait kesehatan reproduksi, supaya dalam melaksanakan tugas dan wewenangnya mampu memberikan pelayanan sesuai dengan kebutuhan PSK. Selain itu tenaga kesehatan harus memberikan motivasi kepada PSK agar rutin melakukan kunjungan ulang dan wajib kondom agar terhindar dari infeksi menular seksual (IMS) dan HIV/AIDS.

3. Pekerja seks komersial

PSK harus rutin memeriksakan ke Puskesmas Gedongtengen hal ini bertujuan untuk memantau kesehatan reproduksi PSK. PSK harus wajib menggunakan kondom agar terhindar dari infeksi menular seksual dan PSK harus mengalihkan pekerjaan yang lebih manusiawi agar tidak dipandang dan direndahkan oleh masyarakat. PSK harus tegas kepada pelanggan dan menolak pelanggan apabila tidak mau menggunakan kondom. 


\section{DAFTAR PUSTAKA}

Arisita Eka Prasetyawati, 2011, Ilmu Kesehatan Masyarakat untuk Kebidanan Holistik, Yogyakarta, Nuha Medika.

Cecep Triwibowo, 2014, Etika dan Hukum Kesehatan, Yogyakarta, Nuha Medika.

Eny Retna Ambarwati,Y, Sriati Rismintari, 2009, Asuhan Kebidanan Komunitas, Yogyakarta, Nuha Medika.

Undang-Undang Dasar 1945

Undang-Undang Nomor 39 Tahun 1999 tentang Hak Asasi Manusia

Undang-Undang Nomor 36 Tahun 2009 tentang Kesehatan

Peraturan Pemerintah Nomor 61 Tahun 2014 tentang Kesehatan Reproduksi 